\title{
PESQUISAS SOBRE GÊNERO E PODER NA LITERATURA CONTEMPORÂNEA: DIÁLOGOS FEMINISTAS
}

\section{RESEARCH ON GENDER AND POWER IN CONTEMPORARY LITERATURE: FEMINIST DIALOGUES}

\author{
Liane Schneider \\ Universidade Federal da Paraíba, UFPB, Joâo Pessoa, PB, Brasil
}

\begin{abstract}
Resumo: No presente artigo discuto como marcas de gênero em textos literários contemporâneos destacam relaçôes de poder e as implícitas desigualdades. Para tanto, enfocamos duas frentes de representação dessas marcas: via violência e opressão vinculadas ao gênero, especificamente no contexto da América do Norte. A partir da produção de teóricos(as) da violência, tais como Nan Stein, Suma Chitnis e Melinda York, e com referência a produçôes crítico-literárias de Rita Terezinha Schmidt, pesquisadora homenageada neste volume, proponho destacar o papel da Literatura (especificamente em Monoceros, de Suzette Mayr) para o questionamento do status quo, que fortalece uma organização social opressiva no que se refere a gênero e sexualidade, marcas essas verificáveis também em grande parte dos discursos críticos veiculados nos espaços da academia, da escola, dos sistemas educacionais como um todo.
\end{abstract}

Palavras chave: Literatura canadense; Violência; Poder; Gênero; Rita Terezinha Schmidt.

Abstract: Along the presente articleI discuss how gender criticism stresses power relations, pointing out the implied inequalities. In this sense, I focus on gender tension and on the way it is related to violence and oppression of some individuals because of their immersion in patriarchal gender systems, analyzing how this is represented in contemporary narratives by women in North America, mainly in Suzette Mayr`s Monoceros. Taking as my theoretical basis the work of some violence experts, such as Nan Stein, Suma Chitnis, and Melinda York, and the critical production of professor Rita Terezinha Schmidt in the Brazilian context, I point out the questioning role literature assumes as a space for unmasking the conservative status quo that perpasses the literary field. How the literary dialogues with the schooling context is also one of my interests along the article, seeing Education as a territory for debate and growth.

Keywords: Canadian literature; Violence; Power; Gender; Rita Terezinha Schmidt.

\section{Introduçáo}

Inicio meu texto inspirada por retalhos de memória, inclusive pelo fato de este número da Fragmentum estar voltado à presença acadêmica da professora Rita Terezinha Schmidt e suas atuaçóes como professora, crítica e debatedora. Desde os anos oitenta do século passado, quando fui graduanda do Curso de Letras da Universidade Federal do Rio Grande do Sul, tive a oportunidade de cursar disciplinas que privilegiavam tanto a Literatura 
e crítica produzida por mulheres, absoluta novidade para mim naquela época, como também a crítica e teoria de cunho feminista. Na verdade, recordo que um ano antes da formatura de minha turma, acredito que em 1984, mais precisamente, fui aluna da professora aqui homenageada e, com certeza, posso dizer que aquelas disciplinas, com conteúdos inovadores e provocativos que nos foram apresentados, abriram novos horizontes de leitura e de interpretação para nossa atuação, afetando as escolhas e as futuras carreiras de grande parte do grupo discente envolvido. A professora Rita T. Schmidt havia recém retornado de seu doutorado nos Estados Unidos, tendo, portanto, um diploma ainda quente, saído do forno, e que se voltava a áreas de estudo (crítica feminista e desconstrucionista) que mal engatinhavam no Brasil. Obviamente, havia algumas poucas outras pesquisadoras trabalhando com tais temáticas, entre as quais menciono as professoras Susana B. Funck e Heloisa Buarque de Holanda, compondo um grupo de vozes pioneiras nessa vertente da crítica e de estudos literários de cunho feminista. De lá para cá, com certeza, essa área de pesquisa expandiuse enormemente: houve ampliaçôes de interesses, bifurcaçóes temáticas, diálogos interdisciplinares e comparativos foram sendo estabelecidos. Mas lembrar dos primeiros alicerces da caminhada me parece algo fundamental num momento em que se aposta mais em discos rígidos e nuvens do que na capacidade do cérebro e coração de recordarem. Portanto, a homenagem à Rita Schmidt proposta pela Fragmentum é, de fato, necessária e merecida.

O texto que desenvolvo aqui, portanto, em alguns momentos, dialoga diretamente com artigos e pronunciamentos de Rita T. Schmidt, mas, mesmo nos momentos em que ela não é a referência citada, a moldura da crítica que desenvolvo estará, como na maior parte do que produzo academicamente, em diálogo com a hoje já vasta e consolidada produçáo de cunho feminista brasileira, configuração com a qual a professora citada certamente colaborou imensamente. Na verdade, memória e relaçóes de troca genuína compóem os principais alicerces de pesquisa em qualquer campo.

Nessa direçáo, minha inspiração para o presente artigo deriva de um pensamento da escritora Cherokee/estadunidendese Marilou Awiakta (1993), que propóe que a solidáo e/ou isolamento vivenciados por um indivíduo seriam experiências piores do que a morte em si, já que o sujeito isolado perde seus vínculos com o grupo, com a comunidade, esvaziando qualquer noção de pertencimento social ${ }^{1}$. Claro que essa autora Cherokee traz tal visão a partir da perspectiva de sua cultura, que em muito se diferencia das ditas ocidentais, especialmente aquelas caracterizadas como

\footnotetext{
${ }^{1}$ Daqui por diante, todas as traduçóes do inglês que aparecem em português săo de nossa responsabilidade.
} 
"urbanas". Porém, as ideias da dimensão da solidão e do isolamento social destacadas pela autora nos levam a considerar como essas experiências têm sido retratadas nas literaturas contemporâneas, ou seja, como se fala e se escreve sobre essas "mortes sociais", isolamentos ou silenciamentos impostos, por atos que tentam calar o outro através de violências de todo o tipo.

Como enfocaremos os elos entre Literatura e poder, daremos destaque a uma narrativa produzida na contemporaneidade que representa o isolamento de personagens com base em (ou em consequência de) sua inserção no sistema de gênero. Isto é, o enredo que ilustrará o debate que propomos é marcado pelo lugar diferenciado no que se refere a representaçôes das relaçóes entre masculino e feminino, entre padróes de comportamento majoritário e minoritário, culturas mais ou menos valorizadas, buscando verificar como essas esferas e polos se relacionam, apontando, inclusive, sua interdependência. Daremos destaque à narrativa produzida por uma jovem escritora canadense, Suzette Mayr (2011), mais especificamente, seu romance Monoceros. Ao longo desse romance, ocorrem atos violentos que determinam tanto o rumo que a narrativa toma, como os desdobramentos que marcam a vida (e a morte) de suas personagens. Portanto, acreditamos ser fundamental nos voltarmos brevemente a uma discussão sobre o que compreendemos por "violência" e "poder".

No caso de Monoceros, Mayr (2011) traz como temática central um episódio de bullying ocorrido em uma escola de ensino médio, bullying esse que acaba resultando no suicídio do aluno alvo de chacotas entre os colegas pelo simples fato de ser abertamente gay e apaixonado por um colega. Há uma forte discussão de valores na narrativa, sendo que a violência discutida deixa de afetar apenas a estória do aluno-vítima, para atingir também todo o sistema educacional em que esse se insere e é por essa perspectiva que abordo a narrativa em tela.

\section{Preconceitos ensinados: embates e resistência}

Considerando especificamente o romance Monoceros, há que se observar que a maior parte das personagens, de uma forma ou outra, têm alguma conexão com a escola católica onde o evento de bullying ocorre, seja como professores, alunos, diretores, conselheiros ou parentes dos jovens que se inseriam na instituição de ensino enfocada. Claro que usar uma escola como o local para desenvolver uma estória sobre jovens náo é novidade. Muitos autores deste século e mesmo dos anteriores escreveram sobre o sistema educacional, a escola em si sendo considerada um lugar ideal 
para representar personagens adolescentes. No romance de Mayr (2011), no entanto, a escola é apresentada praticamente a partir da perspectiva da fileira dos fundos da sala. Como leitores e leitoras, estamos, ao longo da narrativa, distanciados/as de qualquer representação positiva do ambiente de ensino, sendo o processo educativo que nos é apresentado, logo de início, fadado ao fracasso. Além disso, em Monoceros (MAYR, 2011), deparamonos com a inabilidade da escola como instituição de acolhimento no sentido de proteger aqueles dentre seus membros que sofrem em consequência de preconceito e discriminação disseminados pelas camadas sociais presentes.

É impossível negar que as instituições educacionais, em certa medida, são ambientes onde a violência tem se manifestado com vários perfis. Neste artigo, interessa-nos sobremaneira aquela violência que vem se tornando mais conhecida recentemente, especialmente nas últimas décadas do século $\mathrm{XX}$, e em vários países, mas particularmente no contexto da América do Norte. Os incontáveis casos de tiroteio, acessos de fúria e outras manifestaçóes que ocorrem não só em colégios de ensino médio, mas também em escolas primárias e universidades parecem estabelecer uma ligaçáo natural entre o tema "violência" e o sistema escolar. Nesse contexto, frequentemente é possível identificar uma fonte de violência explícita sendo dirigida contra o outro, sendo que esse alvo pode ser outro/a aluno/a, o/a professor/a, exprofessor/a, o/a diretor/a, colegas ou ex-colegas, alguma etapa de bullying geralmente estando envolvida ao longo do processo.

$\mathrm{O}$ bullying tornou-se uma forma de mostrar agressividade e intolerância em relação a outras pessoas sem fazer isso de forma explícita ou física. Provavelmente, o ambiente escolar é o local mais comum para se observar seu funcionamento. A definição de bullying no Webster's new world college dictionary apresenta o que segue: "ato de intimidar pessoas mais fracas ou menores"; é importante, contudo, ter em mente que, em seu sentido arcaico, essa palavra surge em conexão com a ideia de empregarse alguém para praticar violência. Portanto, a ideia de violência já está imediata e explicitamente impregnando o conceito de bullying. Pode-se inferir que o fato de ter sido pensado como uma intimidação em relação a pessoas percebidas como mais fracas caracterizaria o bullying como um elemento em sistemas desiguais de relacionamento nos quais vários jogos psicológicos estão acontecendo. De forma semelhante, discussóes quanto ao significado da palavra violência tornaram-se mais e mais frequentes e interdisciplinares e, portanto, mais difíceis de serem resumidas ou definidas. Assim, temos de abordar o conceito a partir de ângulos diferentes, seguindo o que pesquisadores e especialistas em violência têm desenvolvido sobre a temática. 
Suma Chitnis (1998), em uma conferência na Índia, tentou observar qual seria a característica mais central da violência, se comparada a uma gama de outros tipos de experiências negativas que o indivíduo eventualmente enfrenta. Nesse sentido, ela insiste no seguinte questionamento: "por que a dor ligada à violência é mais dolorosa do que outras dores? O medo, por que é mais poderoso?” (CHITNIS, 1998, p. 11). E ainda faz a seguinte observação: "Em termos gerais, violência é um mecanismo coercitivo para afirmar a vontade de alguém sobre outrem, de forma a desenvolver ou sentir uma sensação de poder [...], o que implica também numa ideia de perpetuação (ou inauguração) do poder de alguém sobre outros que são definidos como sem poder algum" (CHITNIS, 1998, p. 12).

$\mathrm{Na}$ verdade, frequentemente há uma conexão entre violência e violação nos contextos em que os termos se apresentam. De acordo com The Oxford advanced learner's dictionary, "violação" implica "tratar (alguém ou alguma coisa) de forma profana ou desrespeitosa". Assim, seguindo essa definição temos de concordar com Chitnis (1998, p. 13) quando ela afirma que " $[\ldots]$ a essência da violência reside num sentimento de violaçáo, na transgressão daquilo que se considera humano”. Parece óbvio que o bullying deva ser considerado um ato de violação dos traços humanos mínimos da vítima, fazendo (ou tentando fazer) com que o indivíduo alvo sinta-se fraco, deslocado, quase não humano.

Se considerarmos o romance de Mayr (2011) nesse campo semântico, é possível afirmar que ali se apresenta uma forma psicológica de violência, aspecto que se torna parte estrutural da narrativa. $\mathrm{Na}$ verdade, o suicídio cometido por um jovem gay de 17 anos, explicitado já no primeiro capítulo de Monoceros, conduz o desenvolvimento de todo o enredo, determinando a forma como todas as outras personagens relacionam-se entre si. $\mathrm{O}$ primeiro capítulo da narrativa, sugestivamente intitulado "Monday: the end" (Segunda-feira: o fim), em que cada parágrafo é iniciado com a palavra "because" (porque), tenta fazer o impossível, ou seja, tornar um fato absurdo - o suicídio de um jovem - tornar-se explicável, contanto que se possa listar motivos para o acontecido.

No primeiro parágrafo do romance, somos informados do bullying que algumas garotas da escola praticam contra esse estudante específico, grupo liderado por Petra. Esse grupo de garotas não se contenta apenas em escrever com spray a frase "você é um viado" no escaninho da vítima, mas também conseguem pegar o skate dele e arremessá-lo no rio gelado, de onde ele não consegue tirá-lo mais, o objeto ficando submerso na água, aparentemente uma espécie de "enterro aquático" com prenúncios sombrios. Podemos, de 
fato, ler a "submersão" do skate como indicativo da tragédia que se arma ao longo da narrativa. Após isso, o jovem perseguido recebe uma mensagem enviada por Petra que diz: "nós vamos te matar" (MAYR, 2011, p. 10).

Realmente, o caso triangular, nunca assumido, formado por três personagens - Petra, Ginger, seu namorado, e o garoto morto - na verdade, Patrick Furey, cujo verdadeiro nome só nos é apresentado em seu obituário - é, desde o início da narrativa, sugerido como de natureza violenta, tensa e trágica. Os dois rapazes costumavam encontrar-se em um cemitério que ficava entre suas casas, onde Ginger sentia-se mais à vontade por estar longe do olhar alheio, permitindo que ali seus sentimentos pelo rapaz pudessem aflorar. $\mathrm{O}$ dia dos namorados (Valentinés day) acaba sendo a razáo para a desgraça que ocorrerá, já que Petra percebe, nessa data, o que está ocorrendo entre seu namorado e Patrick. Depois de Petra pressionar Ginger sobre o que ocorre, esse, temendo as consequências que poderiam derivar das ameaças da namorada, manda uma mensagem definitiva para Patrick: "Não posso mais andar com você - dessa vez é de verdade - quero meu pingente de volta” (MAYR, 2011, p. 15).

O mencionado pingente, símbolo da ligação amorosa entre os dois rapazes, um objeto que pertencera à mãe de Ginger, já falecida, é um marco da troca sentimental genuína entre eles. Ginger deu-o a Patrick no dia dos namorados, dizendo: "Olhe a rosa encravada na parte da frente... é vermelha. Vermelho significa amor" (MAYR, 2011, p. 12). O garoto aceita o presente, perguntando a Ginger por que ele não conseguia "avermelhá-lo"/ amá-lo na escola. Como leitoras, ainda não sabemos que esse será o último encontro entre eles. O garoto, ao sair do cemitério, veste o suéter de Ginger, sem saber que esse era presente do dia dos namorados que Petra lhe dera horas antes. Por outro lado, Petra fica decepcionada pelo fato de Ginger ter lhe dado rosas amarelas no Valentine's day (Dia dos Namorados). Ela tem certeza que amarelo simboliza amizade, não amor. A cor amarela das flores faz com que ela deseje intensamente a morte de Patrick, já que esse está claramente interferindo em sua relação com o namorado. Quando vê Patrick usando o suéter que deu a Ginger e tendo certeza de que, de fato, algo acontecia entre os dois, o bullying que dirige ao jovem intensifica-se mais e mais.

É importante mencionar que a narrativa indica que o jovem perseguido procurou por ajuda na instituiçáo de ensino antes que as coisas fugissem ao controle. Patrick tentou falar com o conselheiro pedagógico sobre as frases agressivas pintadas sobre seu escaninho, o sumiço que deram em seu skate, vários outros pequenos indícios da perseguição que sofria. Reconhecendo 
algum traço de homoafetividade no conselheiro, Patrick inclusive tenta informá-lo sobre o motivo pelo qual está sendo perseguido por Petra e suas amigas. Contudo, o conselheiro não consegue lidar com essas questôes, nem com quaisquer outras ligadas ao campo da sexualidade, fingindo não entender as insinuaçôes do aluno.

Nan Stein (2007, p. 323), em um texto sobre o crescimento da violência sexual nas escolas primárias e secundárias dos Estados Unidos, depois de anos de pesquisa sobre o sistema escolar, defende que "[...] ao longo das últimas décadas, incidentes de abuso sexual em escolas de ensino básico e médio têm ocorrido com alunos cada vez mais jovens e, ao mesmo tempo, esses têm se tornado mais e mais violentos". Embora nosso interesse central seja discutir como o bullying é representado em Monoceros (MAYR, 2011), e não analisar abusos em termos mais gerais, vários aspectos conectam esses dois conceitos se levarmos em conta o estudo de Stein (2007). A autora refere-se à violência verbal ou psicológica como sendo uma resposta agressiva à aparência das pessoas, sua orientação sexual, sua raça/etnia, seu grupo religioso. Stein argumenta que a dimensão do gênero geralmente fica fora dos levantamentos sobre violência nas escolas. Ela coloca que:

[...] especialistas que pesquisam sobre bullying, via de regra, infelizmente tem falhado ao não considerar as formas pelas quais meninos adolescentes (e homens adultos) exercem um controle impiedoso uns sobre os outros, a partir de noçóes rígidas e convencionais sobre o que é masculinidade e a imposiçấo da heterossexualidade (STEIN, 2007, p. 328).

De acordo com Stein (2007, p.328), não reconhecer esses elementos seria "negar um fator operante na cultura dos meninos, ou seja, o impulso maníaco e o esforço incansável de definir-se como "não gay". A partir dessa constatação, parece claro que a violência escolar deve, sim, ser abordada como um fenômeno engendrado, a fim de que se possa lidar de forma melhor com episódios, por exemplo, de bullying nas escolas. De maneira similar, Melinda York (2011), em seus estudos sobre violência, defende que comunidades fortemente marcadas por paradigmas patriarcais tendam a ser mais violentas em relaçáo a elementos não masculinos, já que a desigualdade institucionalizada faz-se presente nos valores, atitudes e comportamentos desses grupos sociais.

Rita T. Schmidt (2010), em capítulo do livro Raízes e rumos, do GT da ANPOLL, "A mulher na literatura", problematiza o uso fora de contexto do termo "gênero", mostrando preocupação com a despolitização 
reconhecível em alguns trabalhos ou atividades realizadas por pessoas não comprometidas com os estudos literários de cunho feminista:

\begin{abstract}
Docentes, sem qualquer história no feminismo acadêmico ou sem atuação em área correlata de pesquisa, oferecem cursos de pós-graduação em que gênero, destituído de seu caráter relacional, é trabalhado como representação da condiçăo feminina na literatura, sem que isso signifique qualquer compromisso com uma crítica aos efeitos dessas representaçóes e suas imbricaçóes com a produção social de mulheres, como signos em discursos dominantes de instituiçôes tais como a família, a escola, a religiâo, o estado e a própria instituição literária. Reduzindo a categoria de gênero à representação patriarcal da diferença sexual, tal tratamento esvazia o seu potencial epistemológico e político de intervenção na produção de discursos que, ainda hoje, procuram colonizar objetos, corpos e vozes, tanto na academia quanto na cultura, de modo geral (SCHMIDT, 2010, p. 253).
\end{abstract}

Em Monoceros (MAYR, 2011), e na escola que adentramos através dessa narrativa, é interessante observar que, exatamente uma garota, Petra, organiza e direciona a violência contra Patrick, ao tentar reafirmar o papel heterossexual de Ginger, seu namorado e, com certeza, esse elemento da narrativa não é casual. Pode-se até considerar que o nome Petra não foi aleatoriamente escolhido por Mayr. O nome Petra deriva do grego, significando "pedra". Ela nos é apresentada como uma personagem dura, inquebrável, nada flexível, e sua força, no final das contas, acaba tendo um efeito bastante negativo sobre o grupo em que se insere. Quando Petra é informada de que Patrick havia cometido suicídio, simplesmente racionaliza a questáo da seguinte maneira. "Então ele se matou. Que triste. Que ruim. Entáo agora ele vai parar de molestar seu namorado. Que alegria. Tudo que fez foi dizer a ele que arrancaria seu pênis. Tudo que fez foi dizer que o mataria. Claro que havia sido uma brincadeira” (MAYR, 2011, p. 68).

Portanto, Petra surge como uma das defensoras de instituiçôes que, no âmbito da estória e história, defendem com unhas e dentes os lugares comuns e dicotômicos da sexualidade, agindo como repressora daquilo que extrapola os lugares sexuais definidos como padrão pela visão patriarcal. Contudo, vale mencionar que outra personagem feminina em Monoceros (MAYR, 2011) assume, de certa forma, o papel de antagonista em relação à Petra, que é Faraday. Embora Faraday não esteja envolvida na relação triangular estabelecida entre seus colegas de classe, sendo bastante isolada dentro do grupo escolar, ela consegue perceber imediatamente a maldade de Petra. 
Faraday tem uma queda por tudo que seja ligado a unicórnios, suas camisetas e brincos têm sempre tais figuras estampadas. De acordo com o Dictionary of world mythology, de Cotterel (1997), o unicórnio geralmente está ligado a questóes que envolvem castidade e pureza. Faraday, uma jovem isolada, mais conectada a seus unicórnios do que a outros jovens, surpreendentemente traz mais humanidade à estória como um todo. Vivendo mentalmente em um mundo mítico que criou para si como um mecanismo de defesa, Faraday aproxima-se da voz narrativa em Monoceros (MAYR, 2011). Vale observar que o unicórnio, na Astronomia, faz parte da constelação de Monoceros (MAYR, 2011). Assim, Faraday aparece como alguém que é parte de um sistema paralelo, bem organizado, com regras específicas, enfim, um mundo que ocupa um espaço livre de violência e que passa a intitular o romance como um todo. A partir desse lugar mítico, Faraday consegue compreender, desde o início da narrativa, o que está acontecendo em relação a Patrick, enxergando, de imediato, a opressão de gênero que esse sofre.

Quando Patrick comete suicídio e a escola não sabe o que fazer ou como tratar do assunto, ignorando o tema por dias, Faraday suspeita que algo não está sendo esclarecido e pergunta à professora de Inglês: "Sra. Mochinski? Onde está Patrick?, sendo que a professora, um tanto nervosa, responde: "Eu não sei. Ele não veio, obviamente" (MAYR, 2011, p. 19). A professora já sabe o que houve, mas o diretor resolveu proibir o assunto até achar uma forma de tratar melhor da questão. Enquanto isso, a voz narrativa diz a nós algo sobre a relação da professora com o fato: "A mesa do jovem morto está no meio da sala e ela não pode dizer nada aos alunos sobre isso porque o diretor ainda náo desvendou todos os fatos. Por que seria importante desvendar todos os fatos?" (MAYR, 2011, p. 39).

$\mathrm{O}$ romance estrutura-se em torno dos sete dias que se seguem ao suicídio de Patrick, período no qual nada é dito aos colegas de forma oficial, apesar de toda a fofoca que circula sobre seu sumiço. É como se um mundo novo estivesse sendo forjado, onde verdades teriam de emergir. Após isso, a narrativa ocupa-se de mais oito semanas, mencionando cada semana como "Mais uma segunda-feira após a morte de Furey". Mesmo que o jovem esteja morto, é sua presença que conduz e dá fluxo à narrativa.

Ainda assim, o tema central de Monoceros (MAYR, 2011) não é essa morte em particular, e sim, a forma como as pessoas envolvidas naquela instituiçáo de ensino são incapazes de lidar com as causas e com as consequências do suicídio cometido por um de seus membros como resultado das relaçóes desiguais de gênero e de poder que ali se estabelecem. 
Assim, os alunos devem continuar discutindo Romeu e Julieta, a relação entre amor e morte sendo ali trabalhada, sem fazer qualquer referência ao que ocorreu próximo a eles, que também tem a ver com esses dois temas. Talvez essa seja a razão pela qual Monoceros (MAYR, 2011) causa um certo desconforto aos leitores. Há diversos tópicos bastante delicados, mascarados nos diálogos ali construídos. Assim, esse desconforto que percorre o enredo dialoga com uma abjeção mais ampla, o que discutimos a seguir.

\section{Abjeçáo e o desejo rejeitado}

De que forma a ideia de abjeção compóe o enredo de Monoceros (MAYR, 2011)? Na introdução ao livro The Abject of Desire, Kulzbach e Mueller (2007) destacam estratégias de estetização do não estético, buscando problematizar as próprias definiçôes filosóficas envolvidas. Apontando concordância com Menninghaus (2003), as duas autoras citadas defendem que, no campo da produção cultural, o que é percebido como desagradável ou não estético geralmente está atrelado a insights sobre a natureza instável e fragmentária do eu, já que "tudo parece estar em risco em experiências com o desconforto. Esse é um estado de alerta e emergência, uma crise aguda de autopreservação" (KULZBACH; MUELLER, 2007, p. 7). Nesse sentido, Kulzbach e Mueller seguem um caminho similar ao seguido por Julia Kristeva no livro Powers of horror, de 1982.

É de nosso interesse observar que, tanto para Kristeva (1982) quanto para Kulzbach e Mueller (2007), há a percepção do abjeto como um medo individual ou coletivo da "outridade" que emerge em situaçóes bastante diversas, frequentemente evocando de forma concomitante um sentimento de "loathing e fascinação". Assim, Kulzbach e Mueller (2007, p.8) afirmam que "[...] o abjeto, que evoca tanto o loathing como o fascínio, assusta quando se manifesta como uma excreção do corpo, pois esse não é o próprio corpo, mas ainda assim, parte dele". A dualidade de estar ao mesmo tempo incluído e excluído, como elemento desejado e rejeitado, marca o abjeto desde o início, conforme também têm apontado estudos na área de Psicologia e Filosofia realizados por Romanowski (2013).

Kristeva (1982) defende que o primeiro abjeto para qualquer indivíduo é o corpo materno, já que aquela que dá à luz um novo indivíduo tem de expeli-lo a fim de permitir a construçâo de margens que separam ele/ela da mãe, seu outro (m/other). Nesse sentido, “[...] o que é expelido continua a ser percebido como atrativo, mas também como uma ameaça ao eu separado" (KULZBACH; MULLER, 2007, p. 9). Se essas autoras 
referem-se à abjeção como parte necessária da relação mãe/filho(a), uma fase necessária de construção da identidade, podemos considerar que, em Monoceros (MAYR, 2011), o "abjeto" que foi eliminado é o elemento homoerótico.

Patrick Furey sofre bullying e é praticamente expulso do grupo, quase forçado a cometer suicídio, como forma de desaparecer de um corpo social formado pelo grupo de estudantes que náo o aceitam - ele é o elemento homoerótico que provoca o desejo e a rejeição de outros. Assim, Petra surge como uma ferramenta que controla a saída do armário por parte de Ginger. Ela controla o comportamento tanto de Patrick quanto de Ginger, não permitindo que aquela atração homoerótica venha a público, como lemos nas racionalizaçóes de Ginger sobre seus sentimentos em relação a Patrick:

[...] porque sua namorada Petra sabia da verdade. E Ginger não negava que tinha dúvidas sobre estar ou náo apaixonado por Furey, embora é claro que ainda estivesse também apaixonado por Petra. De toda forma, tinha de dizer a Furey que tudo estava terminado dessa vez (MAYR, 2011, p. 51).

É possível perceber oscilaçôes nos pensamentos de Ginger. Ele não tem certeza de seus sentimentos enquanto tenta compreender o que está acontecendo. Ele lembra a última vez em que encontrou Patrick e o jovem confessou estar apaixonado por ele. Ginger apenas considerou que gostaria de "[...] empurrar todas aquelas palavras amontoadas na boca de Patrick, a fim de formar uma bola de gelo, lançando-as de volta" (MAYR, 2011, p. 51). O elemento abjeto, quase editado e deletado, aqui representado por Patrick como um corpo homoerotizado, é percebido tanto como atraente como ameaça, que, segundo Kulzbach e Mueller (2007), é o que ocorre quando o abjeto se torna visível:

Encontros com o abjeto desafiam identidades pessoais e coletivas porque ameaçam as margens do sujeito e vêm acompanhadas de sentimentos de perda e solidão. A fim de escapar da atração dessa perigosa outridade [...] o indivíduo rejeita o abjeto a fim de ser capaz de definir e defender as margens da identidade (MUELLER, 2007, p. 9).

Pode-se também levar em conta o que Iris Marion Young desenvolve sobre o tópico da sujeição. Young (1990) defende que grupos marginalizados, tais como pessoas de cor e homossexuais, frequentemente se tornam vítimas de "[...] um corpo estético que define alguns grupos como feios ou assustadores, produzindo reaçôes de adversidade em relação a eles". Além 
disso, coloca que "[...] a associação entre grupos e o abjeto é socialmente construído; uma vez que o vínculo tenha sido feito, no entanto, a teoria do abjeto descreve como essas associaçóes se prendem a identidade dos indivíduos e suas ansiedades" (YOUNG, 1990, p. 145).

Na verdade, Patrick Furey torna-se a fonte da abjeção como resultado de ter mostrado seus sentimentos abertamente a Ginger, provocando nesse o medo de ser percebido pelos outros como gay; além disso, a sexualidade de Furey também mexe com o conselheiro escolar, já que esse tem uma relação escondida (porque, a seu ver, proibida) com o diretor da escola há mais de uma década, disfarçada, a fim de que esses não percam seus cargos. Nesse sentido, pode-se inferir que a abjeção vinculada a Furey, o elemento expulso, representa, na verdade, como bem colocam Kulzbach e Mueller (2007), uma ameaça a vários dos outros personagens no romance, aproximando o medo do desejo, algo que náo conseguem controlar racionalmente.

Faraday, a jovem fã de unicórnios em Monoceros (MAYR, 2011) considera que esses seres míticos talvez sejam os possíveis salvadores do desconforto e da inadequaçáo que reconhece em sua vida, bem como na de seus colegas de sala. Ao considerar a morte de Furey, as seguintes racionalizações surgem:

\begin{abstract}
Ela queria que o morto tivesse falado com ela; ela poderia ter lhe contado que a ajuda divina viria galopando pelos corredores qualquer dia desses, já havia arranjado tudo, uma benção de unicórnios estava a caminho para salvar todos eles, talvez durante a aula de Inglês, talvez numa segunda de manhá; que dia glorioso seria aquele, uma segunda de relinchos de unicórnios (MAYR, 2011, p. 259).
\end{abstract}

Como mencionamos antes, a pureza e a castidade frequentemente estando atreladas à figura do unicórnio, podemos inferir que Faraday, através dessas consideraçóes, quer dar algum significado mais nobre à morte do colega. Não é ao acaso que esse último capítulo do romance recebe o título de "Os unicórnios". Faraday aparece aí vestida em seu pijama de unicórnios, em casa, concluindo que "[...] náo existe essa coisa de ser normal, ela já havia compreendido isso. [...] Tudo que ela precisa é dos unicórnios e pronto" (MAYR, 2011, p. 259). Faraday adormece e sonha com um grupo de unicórnios que chegam para mudar o mundo:

Eles sentem sua presença, eles pertencem a ela, eles a querem. Mas eles também sentem o odor suado e seminal de morte pela escola, um suor espremido através do medo e do julgamento. A benção dos unicórnios chega, as orelhas deles estão para trás, os dentes descobertos e começam 
a relinchar. Viram os olhos, mordem as paredes, chutam os tijolos com as pernas da frente, chutam alto com as pernas de trás. Urinando e defecando em fúria, um relincha e todos relincham (MAYR, 2011, p. 260).

Animais míticos, sonhados e pressentidos por Faraday, finalmente derrubam aquela escola, seus prédios, seus alicerces, e a jovem descreve tal ato como uma "bênçấo destruidora" (MAYR, 2011, p. 261). A presença dos unicórnios, ao final do romance, sugere não apenas o poder da imaginação e da criatividade para que limites impostos sejam ultrapassados, mas também a importância de se aceitar que atração e rejeição são forças pessoais e políticas em jogo em qualquer interação humana, que só se tornam problemáticas quando violentamente suprimidas ou abafadas.

\section{Consideraçóes finais}

O clima de morte e de cemitério presente ao longo do romance de Mayr (2011), os sentimentos mostrados como "vermelhos" apenas quando escondidos, a falsa relação amarelada entre Petra e Ginger, as relaçóes desprovidas de significado estabelecidas entre os estudantes, entre os trabalhadores, o diretor, o conselheiro daquela escola católica e caótica, até mesmo o conteúdo quase sem sentido aprendido dia após dia na instituição de ensino, todos esses aspectos presentes em Monoceros (MAYR, 2011) questionam não apenas a falta de perspectivas na vida de Patrick, mas no sistema escolar ali apresentado. Concordando com Compagnon (2003), quando esse defende que o significado é um efeito da experiência do leitor/a, sabemos que somos convidados por Mayr (2011) a preencher as lacunas e parêntesis expostos no texto. Ao mesmo tempo que se precisa preencher as tais lacunas, somos convidadas a sair de nossa zona de conforto náo apenas em resultado das estratégias da narrativa, mas também devido ao tópico desenvolvido. Na verdade, o enredo indica a incapacidade do sistema escolar em lidar com novos valores e comportamentos, mas também com formas alternativas de aprender e produzir conhecimento - um conhecimento que náo pode ser visto como totalmente separado da experiência da vida real, com toda a sua intensidade e, por vezes, suas erupçôes de violência.

Por essa razão, Monoceros (MAYR, 2011) pode ser lido como um chamamento à sociedade e, mais especificamente, ao sistema escolar - e não apenas no contexto canadense, mas também em termos bem mais amplos, às escolas espalhadas pelo mundo. Literatura produzida sobre o tópico da violência e da opressão, na verdade, pode auxiliar na abordagem de assuntos 
bastante difíceis, talvez devido à ideia de abjeção e rejeição estar muitas vezes aí imersa. Através da leitura de Monoceros (MAYR, 2011) e da discussão literária que disseca sua forma narrativa, é possível apontar situaçóes reais ou fictícias - em que alguma humanidade está sendo negada a alguns indivíduos - sejam mulheres, homens, brancos, não-brancos, heterossexuais ou não. Além disso, é interessante perceber que, no romance de Mayr (2011), o bem e o mal estão vinculados tanto a garotas como a garotos, mulheres e homens, dependendo do quanto eles colocam em jogo a fim de se sentirem no controle As escolas poderiam (e deveriam) ser lugares onde ocorresse o convite à discussão mais promissora dos significados - positivos e negativos - ligados tanto ao que se supóe masculino quanto ao que se tem como feminino, evitando o crescimento da violência, pelo menos da violência extrema em relação a gênero, que desafia a sobrevivência de sujeitos que não acham lugar para si nos parâmetros convencionais - leia-se, heterossexuais - do desejo sexual. Acredito que leituras e críticas de Monoceros (MAYR, 2011) e de outras narrativas semelhantes que se atenham apenas a aspectos estruturais deixam de enxergar e destacar o caráter provocativo, perturbador que, inclusive, a própria estória faz questão de destacar - uma morte provocada pela não aceitaçáo do comportamento e definiçáa sexual de um jovem adolescente que não se enquadra na heterossexualidade imposta. Pelo viés do gênero, da crítica feminista, com interesse em compreender os emaranhados entre poder e violência presentes na narrativa de Mayr (2011), ganhamos em termos de competência de leitura, de compreensão de outras camadas do texto, desenterrando esse personagem, Furey, e seu skate, do fundo do lago gelado e, depois, congelado em que estivera submerso.

Por fim, gostaria de afirmar que a professora Rita Terezinha Schmidt, ao longo de anos e anos de ensino e de produção crítica na área da análise literária, especialmente de cunho feminista, fez com que meu olhar crítico se tornasse mais competente do que seria sem as imersôes critico-teóricas a que tive acesso como sua aluna, leitora de seus trabalhos e de suas pesquisas. O presente estudo surge nesse diálogo, nessa zona de contato e de troca, esperando que a interlocução acadêmica com a homenageada desse volume possa se manter estimulante e desafiadora por muitos anos, principalmente nas frentes feministas e culturais afinadas com a contemporaneidade, sempre ainda tão necessárias. 


\section{Referências}

AWIAKTA, M. Cherokee Eden: an alternative to the apple. In: FIFE, Connie (Ed.). The colour of resistance: a contemporary collection of writing by aboriginal women. Toronto, Sister vision press, 1993. p. 244251.

CHITNIS, S. The concept of violence. In: KUDCHEDKAR, S.; ALISSA, S. (Ed.). Violence against women, women against violence. Delhi: Pencraft International, 1998. p. 11-18.

COMPAGNON, A. O demônio da teoria. Belo Horizonte: UFMG, 2001.

COTTEREL, A. A dictionary of world mythology. Oxford: Oxford University Press, 1997.

KRISTEVA, J. Power of horror: an essay on abjection. Translation by Leon S. Roudiez. New York: Columbia University Press, 1982.

KULZBACH, K.; MUELLER, M. The abject of desire: the aesheticization of the unaesthetic in contemporary literature and culture. Amsterdam: Rodopi, 2007.

MAYR, S. Monoceros. Toronto: Coach House Books, 2011.

ROMANOWSKI, A. Subject/abject/object: reconfiguring desire in contemporary French cultural production. Pittsburgh: University of Pittsburgh, 2013.

SCHMIDT, Rita Terezinha. Revisitando a mulher na literatura: horizontes e desafios. In:

STEIN, N. D. Locating a secret problem: sexual violence in elementary and secondary schools. In: O'TOOLE, L.; CHIFFMAN, J.; EDWARDS, M. (Ed.). Gender violence: interdisciplinary perspectives. 2nd. ed. New York: NYUP, 2007. p. 323-332.

THE OXFORD ADVANCED LEARNER'S DICTIONARY. Oxford: Oxford University Press, 1974.

WEBSTER'S NEW WORLD COLLEGE DICTIONARY. 5th ed. New York: Webster's New World, 2014. 
YORK, M. Gender attitudes and violence against women. El Paso: LFB Scholarly Publishing, 2011.

YOUNG, I. M. Justice and the politics of difference. Princeton: Princeton University Press, 1990. 